\title{
RESEARCH ON TWO-TARIFF CONTRACT CONSIDERING THE CORPORATE SOCIAL RESPONSIBILITY OF COMPETING SUPPLIERS
}

\author{
Yufei Huang, Pin Zhuang
}

School of Economics and Management, Nanjing University of Aeronautics and Astronautics, Nanjing 211106, China

DOI: 10.46609/IJSSER.2020.v05i07.018 URL: https://doi.org/10.46609/IJSSER.2020.v05i07.018

\begin{abstract}
Taking a supply chain composed of two competing suppliers and a single retailer as the research object, this paper establishes a Stackelberg game model to solve the optimal decision under the premise that the retailer assumes CSR and under the single supplier assumes CSR and both suppliers assume CSR situations respectively, analyzes the impact of different CSR input modes and the competition coefficient between suppliers on the total profit of the supply chain, and use two-tariff contract to coordinate the supply chain. It is found that when the contract parameters satisfy certain conditions, the two-tariff contract can coordinate the supply chain effectively under different CSR input modes; and compared with the way that the single supplier assumes CSR, the total profit of the supply chain is lower but the total CSR level is higher under the way that both suppliers assume CSR which has no obvious advantage; and competition among suppliers has a negative impact on the profits and CSR level of each member of the supply chain.
\end{abstract}

Keywords: Corporate social responsibility; competing suppliers; two-tariff contract

\section{INTRODUCTION}

In recent years, the importance of corporate social responsibility (CSR) has been enhanced by the change of development model in many developed countries, the improvement of consumers' awareness of environmental protection and the improvement of employees' awareness of protecting individual rights at work.CSR requires that enterprises no longer take the pursuit of profit as the only goal, and emphasizes the concern for the environment, society, consumers and other stakeholders. Many scholars have found that CSR has a positive impact on corporate value and consumers' buying intentions. Xie et al. (2019) ${ }^{[1]}$ find that consumers' perception of CSR leads to consumers' positive attitude towards corporate brand promotion. Mishra (2017) ${ }^{[2]}$ and Huang (2012 $)^{[3]}$ find that CSR plays a positive role in improving corporate value. Deng et al. 
International Journal of Social Science and Economic Research

ISSN: $2455-8834$

Volume: 05, Issue: 07 "July 2020"

$(2017)^{[4]}$ point out that CSR has a direct positive effect on consumers' purchase intention through empirical test. However, many enterprises still lack the enthusiasm to fulfill CSR. According to the 《Blue Book on Corporate Social Responsibility (2018)》, the CSR development index of Top 300 enterprises in China is still in the initial stage, and more than $40 \%$ of them are still in the bystander stage, with weak CSR awareness and frequent CSR failures. For example, Pinduoduo turned a blind eye to the prevalence of fakes on its platform; Sanquan frozen dumplings have been detected swine fever virus and so on.

In order to solve how to arouse the enthusiasm of enterprises to fulfill the CSR and how to seek a balance between the costs and benefits caused by CSR, many scholars began to use game theory and other methods to study the supply chain decision considering CSR, and realize the coordination of supply chain considering CSR by using contracts. Ma et al. (2017) ${ }^{[5]}$ consider the CSR efforts of manufacturer and the sales ability of retailer, and establish wholesale price contract model and two-tariff contract model respectively under the condition of information asymmetry. Goering $(2012)^{[6]}$ investigates the optimal game solution of applying two-tariff contract when the retailer fulfills CSR or the manufacturer fulfills CSR. Liu et al. $(2019)^{[7]}$ consider the retailer's CSR and study the optimal decision with or without the government subsidy by using a Stackelberg game model. Bian et al. (2016) ${ }^{[8]}$ design the CSR incentive contracts under Bertrand and Cournot competitive modes of differentiated goods. Hsueh (2014) ${ }^{[9]}$ uses revenue sharing contract to improve CSR performance and profit of supply chain. Fan et al. (2017) ${ }^{[10]}$ coordinate the supply chain with quantity discount contract and quality improvement cost contract on the premise of considering the CSR behavior of the manufacturer. Xing et al. (2017) ${ }^{[11]}$ study the optimal strategy of supply chain under the circumstance that the service integrator fulfills CSR and the service provider makes service quality efforts. Duan et al. (2016) ${ }^{[12]}$ establish a Nash game model in which both the logistics service integrator and the logistics service provider fulfill CSR, and realize supply chain coordination by using revenue sharing contract. Li et al. (2020) ${ }^{[13]}$ study the impact of CSR on the closed-loop supply chain and the best CSR undertaking mode of the supply chain, and finally coordinate the supply chain with quantity discount and CSR cost-sharing contract.

Most of the above literature only studies the "one-to-one" simple supply chain structure. However, with the intensification of competition, many enterprises often choose multiple suppliers to supply products to reduce the risk of shortage and improve the quality of, or choose multiple retailers to sell products to broaden sales channels and increase profits. Accordingly, many scholars began to study the decision-making and coordination under the "many-to-one" supply chain structure. Huang (2018) ${ }^{[14]}$ studies the closed-loop supply chain that considers the competition of multiple retailers in the recycling process, and analyzes the impact of retailers' 
competition degree on profits. Zhou et al. (2018) ${ }^{[15]}$ study the impact of government carbon tax policies on pricing decisions and social welfare considering multiple competitive retailers and bilateral monopolies. Wang and $\mathrm{Li}(2019)^{[16]}$ consider the promotion competition between two retailers and realize supply chain coordination by using cost-sharing contract under the asymmetric promotion cost coefficient of retailers. Sun et al. (2014) ${ }^{[17]}$ study the coordination of a two-level supply chain consisting of two competing manufacturers and a single retailer with a level of effort, and realize the coordination of the supply chain by using the revenue sharing contract. Qin (2018) ${ }^{[18]}$ studies the online shopping service supply chain consisting of a single online store and two third-party logistics providers, and realizes partial coordination of the supply chain by using the partial side-payment contract. Wang and Gao (2016) ${ }^{[19]}$ solve the optimal pricing decision under decentralized decision making, single manufacturer and retailer alliance, two manufacturer alliance and tripartite alliance respectively.

To sum up, most of the literature only focuses on the CSR behavior of one supply chain member, lacking the research on the CSR behavior of multiple supply chain members at the same time, and without analyzing the impact of different CSR undertaking modes on the profit of the supply chain. Moreover, few literature studies the coordination problem of CSR supply chain under the "many-to-one" supply chain structure. Therefore, we study the supply chain consisting of two competing suppliers and a single retailer. Under the premise that the retailer fulfills CSR, a decision model and a two-tariff contract model are established respectively in the case that a single supplier fulfills CSR and both suppliers fulfill CSR to solve the following problems :(1) in the two situations, what CSR and price strategies should supply chain members adopt to maximize the total profit of the supply chain;(2) What coordination mechanism can be adopted to realize the coordination of supply chain;(3) Considering the competition between suppliers, whether it is more advantageous for both suppliers to undertake CSR than for a single supplier;(4) How the degree of competition among suppliers affects the optimal strategy and total profit.

\section{MODEL ASSUMPTIONS AND PARAMETER DESCRIPTION}

\section{The relevant parameters are explained as follows:}

Table 1: Parameter description

\begin{tabular}{cccc}
\hline parameter & description & parameter & description \\
\hline$m$ & market size & $C_{\mathrm{m}}\left(y_{m}\right)$ & retailer's CSR cost \\
$w_{i}$ & wholesale prices of supplier $i$ & $C_{s i}\left(y_{s i}\right)$ & supplier $i$ 's CSR cost \\
$D_{i}$ & demand of supplier $i$ & $c_{m}$ & retailer's CSR costcoefficient
\end{tabular}


International Journal of Social Science and Economic Research

ISSN: $2455-8834$

Volume: 05, Issue: 07 "July 2020"

\begin{tabular}{cccc}
$D$ & The total market demand & $c_{s i}$ & supplier $i$ 's CSR cost coefficient \\
$c$ & production cost of suppliers & $T_{i}$ & $\begin{array}{c}\text { transfer payment } \\
p\end{array}$ \\
retail price of the product & $k$ & coefficient of competition between \\
$x_{i}$ & retailer's marginal profits & $\alpha$ & retailer's CSR sensitivity coefficient \\
$y_{m}$ & retailer's CSR level & $\beta$ & suppliers' CSR sensitivity coefficient \\
$y_{s i}$ & supplier $i$ 's CSR level & & \\
\hline
\end{tabular}

Relevant assumptions are as follows:

Assumption 1: The supply chain is dominated by the retailer, and all the members of the supply chain are risk-neutral and completely rational.

Assumption 2: The products offered by the two suppliers are alternative. We mainly considers the competition of suppliers in CSR efforts.

Assumption 3: Under the situation S, we assume that supplier 1 and retailer fulfill CSR; and under the situation D, we assume that supplier 1, supplier 2 and retailer fulfill CSR. Considering that CSR cost has the characteristic of increasing marginal cost, we set the retailer CSR cost function as $C_{\mathrm{m}}\left(y_{m}\right)=\frac{1}{2} c_{m} y_{m}^{2}, \quad C_{m}^{\prime}\left(y_{m}\right) \geq 0, C_{m}^{\prime \prime}\left(y_{m}\right) \geq 0$, and the suppliers CSR cost function as $C_{\mathrm{si}}\left(y_{s i}\right)=\frac{1}{2} c_{s i} y_{s i}^{2}, \quad C_{s i}^{\prime}\left(y_{s i}\right) \geq 0, \quad C_{s i}^{\prime \prime}\left(y_{s i}\right) \geq 0, \quad i=1,2$ 。

Assumption 4: To ensure the profitability of suppliers and the retailer, let $p>w_{1}>c$ and $p>w_{2}>c, \quad x_{i}=p-w_{i}$ 。

Assumption 5: Under the situation S, supplier 2 does not fulfill CSR, so there is no competition in CSR performance. Referring to Wang ${ }^{[20]}$ 's setting of linear demand function considering effort level, we define the demand function of each supplier as follows: $D_{1}=m-p+\alpha y_{m}+\beta y_{s 1}$; $D_{2}=m-p+\alpha y_{m}$ 。

Assumption 6: Under the situation D, since the products provided by the two suppliers are alternative and we mainly consider the competitive effect of suppliers' CSR performance, referring to the setting of market demand by $\mathrm{Ma}{ }^{[5]}$, we define the demand function of each supplier as follows: $D_{1}=m-p+\alpha y_{m}+\beta y_{s 1}-k y_{s 2} ; \quad D_{2}=m-p+\alpha y_{m}+\beta y_{s 2}-k y_{s 1}$. That is, the demand of each supplier is negatively affected by the price and CSR level of competing suppliers, and 
positively affected by the CSR level of the retailer and their own. Since the demand is more sensitive to its own CSR level than that of the competing supplier, we set $\beta>k$.

\section{SINGLE SUPPLIER FULFILLS CSR (SITUATION S)}

We define the profit function of the retailer and suppliers as follows:

$$
\begin{gathered}
\pi_{m}=\left(p-w_{1}\right)\left(m-p+\alpha y_{m}+\beta y_{s 1}\right)+\left(p-w_{2}\right)\left(m-p+\alpha y_{m}\right)-\frac{1}{2} c_{m} y_{m}^{2} \\
\pi_{s 1}=\left(w_{1}-c\right)\left(m-p+\alpha y_{m}+\beta y_{s 1}\right)-\frac{1}{2} c_{s 1} y_{s 1}^{2} \\
\pi_{s 2}=\left(w_{2}-c\right)\left(m-p+\alpha y_{m}\right)
\end{gathered}
$$

\subsection{Centralized decisions (SC)}

In this case, the retailer, supplier 1 and supplier 2 determine $p, y_{m}$ and $y_{s 1}$ as a whole with the goal of maximizing the total profit of the supply chain.

Proposition 1. Under the situation S, the optimal equilibrium solution of the centralized decision is:

$$
\begin{aligned}
& p^{S C *}=\frac{2(m+c) c_{m} c_{s 1}-4 \alpha^{2} c c_{s 1}-\beta^{2} c c_{m}}{4 c_{m} c_{s 1}-4 \alpha^{2} c_{s 1}-\beta^{2} c_{m}} \\
& y_{m}^{S C *}=\frac{4(m-c) \alpha c_{s 1}}{4 c_{m} c_{s 1}-4 \alpha^{2} c_{s 1}-\beta^{2} c_{m}} \\
& y_{s 1}^{S C *}=\frac{2 \beta c_{m}(m-c)}{4 c_{m} c_{s 1}-4 \alpha^{2} c_{s 1}-\beta^{2} c_{m}}
\end{aligned}
$$

Proof. The total profit of the supply chain is:

$$
\pi=(p-c)\left(2 m-2 p+2 \alpha y_{m}+\beta y_{s 1}\right)-\frac{1}{2} c_{m} y_{m}^{2}-\frac{1}{2} c_{s 1} y_{s 1}^{2}
$$

Take the derivative of the total supply chain profit with respect to $p, y_{m}$ and $y_{s 1}$ by setting $\partial \pi / \partial p=0, \partial \pi / \partial y_{m}=0$ and $\partial \pi / \partial y_{s 1}=0$, then we can solve the optimal equilibrium solution. 
After substituting the optimal equilibrium solution into Eq. (4), we find that:

$$
\pi^{S C *}=\frac{2(m-c)^{2} c_{m} c_{s 1}}{4 c_{m} c_{s 1}-4 \alpha^{2} c_{s 1}-\beta^{2} c_{m}}
$$

Proposition 2. Under the situation S, when the sensitivity coefficient of CSR increases, the optimal CSR level of each member and the total profit of the supply chain increase.

Proof. $\frac{\partial \pi^{S C *}}{\partial \alpha}=\frac{16(m-c)^{2} \alpha c_{m} c_{s 1}^{2}}{\left[4 c_{m} c_{s 1}-4 \alpha^{2} c_{s 1}-\beta^{2} c_{m}\right]^{2}}>0, \quad \frac{\partial \pi^{S C *}}{\partial \beta}=\frac{4(m-c)^{2} \beta c_{m}^{2} c_{s 1}}{\left[4 c_{m} c_{s 1}-4 \alpha^{2} c_{s 1}-\beta^{2} c_{m}\right]^{2}}>0$.

Because $y_{m}^{S C *}>0$, so $4 c_{m} c_{s 1}+4 \alpha^{2} c_{s 1}-\beta^{2} c_{m}>4 c_{m} c_{s 1}-4 \alpha^{2} c_{s 1}-\beta^{2} c_{m}>0$ and $m-c>0, \quad$ we $\quad$ can $\quad$ find $\frac{\partial y_{m}^{S C *}}{\partial \alpha}=\frac{4(m-c) c_{s 1}\left(4 c_{m} c_{s 1}+4 \alpha^{2} c_{s 1}-\beta^{2} c_{m}\right)}{\left[4 c_{m} c_{s 1}-4 \alpha^{2} c_{s 1}-\beta^{2} c_{m}\right]^{2}}>0$. Similarly, we can find $\frac{\partial y_{s 1}^{S C *}}{\partial \beta}>0$.

The Proposition 2 shows that with the improvement of consumers' CSR recognition, the total profit of the supply chain will increase, and enterprises will have more motivation to fulfill CSR, which will benefit consumers in the end. Therefore, enterprises can jointly publicize CSR to make consumers understand the concept and role of CSR to improve consumers' CSR recognition.

\subsection{Decentralized decisions (SD)}

In this case, we establish a Stackelberg game model dominated by the retailer and followed by suppliers. The decision sequence is as follows: Firstly, the retailer determines $p$ and $y_{m}$; Then, the supplier1 determines $w_{1}$ and $y_{s 1}$, and the supplier 2 determines $w_{2}$ at the same time. For the convenience of calculation, we introduce the retailer's profit margin $x_{i}$ in this section, $x_{i}=p-w_{i}$ , $i=1,2$.

Proposition 3. Under the situation S, the optimal equilibrium solution of the decentralized decision is:

$$
\begin{gathered}
p^{S D *}=\frac{c_{m}\left[\left(\beta^{4}+2 c_{s 1}^{2}\right)(c+3 m)-\beta^{2} c_{s 1}(3 c+7 m)\right]-c \alpha^{2}\left(\beta^{2}-2 c_{s 1}\right)^{2}}{2 c_{m}\left(2 \beta^{4}-5 c_{s 1} \beta^{2}+4 c_{s 1}^{2}\right)-\alpha^{2}\left(\beta^{2}-2 c_{s 1}\right)^{2}} \\
y_{m}^{S D *}=\frac{\alpha(m-c)\left(\beta^{2}-2 c_{s 1}\right)^{2}}{2 c_{m}\left(2 \beta^{4}-5 c_{s 1} \beta^{2}+4 c_{s 1}^{2}\right)-\alpha^{2}\left(\beta^{2}-2 c_{s 1}\right)^{2}}
\end{gathered}
$$




$$
\begin{gathered}
w_{1}^{S D *}=c+\frac{c_{m} c_{s 1}(m-c)\left(2 c_{s 1}-\beta^{2}\right)}{2 c_{m}\left(2 \beta^{4}-5 c_{s 1} \beta^{2}+4 c_{s 1}^{2}\right)-\alpha^{2}\left(\beta^{2}-2 c_{s 1}\right)^{2}} \\
w_{2}^{S D *}=c+\frac{c_{m}(m-c)\left(\beta^{4}-3 \beta^{2} c_{s 1}+2 c_{s 1}^{2}\right)}{2 c_{m}\left(2 \beta^{4}-5 c_{s 1} \beta^{2}+4 c_{s 1}^{2}\right)-\alpha^{2}\left(\beta^{2}-2 c_{s 1}\right)^{2}} \\
y_{s 1}^{S D *}=\frac{c_{m} \beta(m-c)\left(2 c_{s 1}-\beta^{2}\right)}{2 c_{m}\left(2 \beta^{4}-5 c_{s 1} \beta^{2}+4 c_{s 1}^{2}\right)-\alpha^{2}\left(\beta^{2}-2 c_{s 1}\right)^{2}}
\end{gathered}
$$

Proof. In this section, we use the inverse induction method to solve the equilibrium solution of the subgame model.

Firstly, the supplier1 determines $w_{1}$ and $y_{s 1}$, and the supplier 2 determines $w_{2}$ at the same time.

Take the first derivative of Eq. (2) with respect to $w_{1}$ and $y_{s 1}$ by setting $\partial \pi_{s 1} / \partial w_{1}=0$ and $\partial \pi_{s 1} / \partial y_{s 1}=0$, and take the first derivative of Eq. (3) with respect to $w_{2}$ by setting $\partial \pi_{s 2} / \partial w_{2}=0$. We have:

$$
\begin{gathered}
w_{1}=\frac{c_{s 1}\left(m+\alpha y_{m}-p\right)+c\left(c_{s 1}-\beta^{2}\right)}{c_{s 1}-\beta^{2}} \\
y_{s 1}=\frac{\beta\left(m+\alpha y_{m}-p\right)}{c_{s 1}-\beta^{2}} \\
w_{2}=m-p+\alpha y_{m}+c
\end{gathered}
$$

Then, the retailer determines $p$ and $y_{m}$.

Substitute Eqs. (5)-(7) into Eq. (1), and derive the first-order conditions on $p$ and $y_{m}$. We can find the optimal equilibrium solution of $p$ and $y_{m}$ :

$$
\begin{gathered}
p^{S D *}=\frac{c_{m}\left[\left(\beta^{4}+2 c_{s 1}^{2}\right)(c+3 m)-\beta^{2} c_{s 1}(3 c+7 m)\right]-c \alpha^{2}\left(\beta^{2}-2 c_{s 1}\right)^{2}}{2 c_{m}\left(2 \beta^{4}-5 c_{s 1} \beta^{2}+4 c_{s 1}^{2}\right)-\alpha^{2}\left(\beta^{2}-2 c_{s 1}\right)^{2}} \\
y_{m}^{S D *}=\frac{\alpha(m-c)\left(\beta^{2}-2 c_{s 1}\right)^{2}}{2 c_{m}\left(2 \beta^{4}-5 c_{s 1} \beta^{2}+4 c_{s 1}^{2}\right)-\alpha^{2}\left(\beta^{2}-2 c_{s 1}\right)^{2}}
\end{gathered}
$$

After substituting Eqs. (8) and (9) into Eqs. (5)-(7), we can obtain the optimal equilibrium solution of the decentralized decision. Then, substitute the optimal equilibrium solution into Eqs. (1)-(3), we can obtain the optimal profit of each member in this case: 


$$
\begin{aligned}
& \pi_{s 1}^{S D *}=\frac{c_{s 1} c_{m}^{2}(m-c)^{2}\left(2 c_{s 1}-\beta^{2}\right)^{3}}{2\left[2 c_{m}\left(2 \beta^{4}-5 c_{s 1} \beta^{2}+4 c_{s 1}^{2}\right)-\alpha^{2}\left(\beta^{2}-2 c_{s 1}\right)^{2}\right]^{2}} \\
& \pi_{s 2}^{S D *}=\frac{c_{m}^{2}(m-c)^{2}\left(\beta^{4}-3 c_{s 1} \beta^{2}+2 c_{s 1}^{2}\right)^{2}}{\left[2 c_{m}\left(2 \beta^{4}-5 c_{s 1} \beta^{2}+4 c_{s 1}^{2}\right)-\alpha^{2}\left(\beta^{2}-2 c_{s 1}\right)^{2}\right]^{2}} \\
& \pi_{m}^{S D *}=\frac{c_{m}(m-c)^{2}\left(\beta^{2}-2 c_{s 1}\right)^{2}}{4 c_{m}\left(2 \beta^{4}-5 c_{s 1} \beta^{2}+4 c_{s 1}^{2}\right)-2 \alpha^{2}\left(\beta^{2}-2 c_{s 1}\right)^{2}} \\
& \pi^{S D *}=\pi_{m}^{S D *}+\pi_{s 1}^{S D *}+\pi_{s 2}^{S D *}
\end{aligned}
$$

\subsection{Two-tariff contract (SF)}

Since there is a double marginal effect in decentralized decision that is not conducive to the development of supply chain, in this case, the retailer provides supplier 1 with the two-tariff $\operatorname{contract}\left(x_{1}^{S F}, T_{1}^{S F}\right)$ and supplier 2 with the two-tariff $\operatorname{contract}\left(x_{2}^{S F}, T_{2}^{S F}\right)$ respectively.

Proposition 4. Under the situation $\mathrm{S}$, the two-tariff contract can realize the coordination of the supply chain, so that the optimal decision of supply chain members can reach the level under the centralized decision, and the pareto improvement of profits can be realized.

Proof. The profit functions of retailer, supplier 1 and supplier 2 under contract coordination are:

$$
\begin{gathered}
\pi_{m}=x_{1}^{S F}\left[m-\left(x_{1}^{S F}+w_{1}\right)+\alpha y_{m}+\beta y_{s 1}\right]+x_{2}^{S F}\left[m-\left(x_{2}^{S F}+w_{2}\right)+\alpha y_{m}\right]-\frac{1}{2} c_{m} y_{m}^{2}+T_{1}^{S F}+T_{2}^{S F} \\
\pi_{s 1}=\left(w_{1}-c\right)\left[m-\left(x_{1}^{S F}+w_{1}\right)+\alpha y_{m}+\beta y_{s 1}\right]-\frac{1}{2} c_{s 1} y_{s 1}^{2}-T_{1}^{S F} \\
\pi_{s 2}=\left(w_{2}-c\right)\left[m-\left(x_{2}^{S F}+w_{2}\right)+\alpha y_{m}\right]-T_{2}^{S F}
\end{gathered}
$$

Taking the first derivative of Eq. (12) with respect to $w_{2}$ by setting $\partial \pi_{s 1} / \partial w_{2}=0$, we can find that $2 w_{2}=m-x_{2}+c+\alpha y_{m}$. And because $w_{2}=p-x_{2}$, we can find that $x_{2}=2 p-m-c-\alpha y_{m}$. Because under contract coordination, the optimal strategy of supply chain members is the same as that under centralized decision, that is, $p^{S F *}=p^{S C *}, y_{m}^{S F *}=y_{m}^{S C *}, y_{s 1}^{S F *}=y_{s 1}^{S C *}$. Then we can obtain $x_{2}^{S F *}=\frac{(m-c) \beta^{2} c_{m}}{4 c_{m} c_{s 1}-4 \alpha^{2} c_{s 1}-\beta^{2} c_{m}}$. 
Taking the first derivative of Eq. (11) with respect to $y_{s 1}$ by setting $\partial \pi_{s 1} / \partial y_{s 1}=0$, we can find that $y_{s 1}=\frac{\beta\left(p-x_{1}-c\right)}{c_{s 1}}$. Because under contract coordination, the optimal strategy of supply chain members is the same as that under centralized decision, that is, $p^{S F *}=p^{S C *}, y_{m}^{S F *}=y_{m}^{S C *}, y_{s 1}^{S F *}=y_{s 1}^{S C *}$. Then we can obtain $x_{1}^{S F *}=0$.

Finally, the value range of transfer payment $T_{1}^{S F}$ and $T_{2}^{S F}$ can be obtained from $\pi_{m}^{S F *} \geq \pi_{m}^{S D *}$, $\pi_{s 1}^{S F *} \geq \pi_{s 1}^{S D *}$ and $\pi_{s 2}^{S F *} \geq \pi_{s 2}^{S D *}$. Due to the complexity of the expression, the specific range will be given in the numerical analysis.

\section{BOTH SUPPLIERS FULFILL CSR (SITUATION D)}

We define the profit function of the retailer and suppliers as follows:

$$
\begin{gathered}
\pi_{m}=\left(p-w_{1}\right)\left(m-p+\alpha y_{m}+\beta y_{s 1}-k y_{s 2}\right)+\left(p-w_{2}\right)\left(m-p+\alpha y_{m}+\beta y_{s 2}-k y_{s 1}\right)-\frac{1}{2} c_{m} y_{m}^{2} \\
\pi_{s 1}=\left(w_{1}-c\right)\left(m-p+\alpha y_{m}+\beta y_{s 1}-k y_{s 2}\right)-\frac{1}{2} c_{s 1} y_{s 1}^{2} \\
\pi_{s 2}=\left(w_{2}-c\right)\left(m-p+\alpha y_{m}+\beta y_{s 2}-k y_{s 1}\right)-\frac{1}{2} c_{s 2} y_{s 2}^{2}
\end{gathered}
$$

\subsection{Centralized decisions (DC)}

In this case, the retailer, supplier 1 and supplier 2 determine $p, y_{m}, y_{s 1}$ and $y_{s 2}$ as a whole with the goal of maximizing the total profit of the supply chain.

Proposition 5. Under the situation D, the optimal equilibrium solution of the centralized decision is:

$$
\begin{gathered}
p^{D C *}=\frac{2(m+c) c_{m} c_{s 1} c_{s 2}-c c_{m}(\beta-k)^{2}\left(c_{s 1}+c_{s 2}\right)-4 \alpha^{2} c c_{s 1} c_{s 2}}{4 c_{m} c_{s 1} c_{s 2}-c_{m}(\beta-k)^{2}\left(c_{s 1}+c_{s 2}\right)-4 \alpha^{2} c_{s 1} c_{s 2}} \\
y_{m}^{D C *}=\frac{4(m-c) \alpha c_{s 1} c_{s 2}}{4 c_{m} c_{s 1} c_{s 2}-c_{m}(\beta-k)^{2}\left(c_{s 1}+c_{s 2}\right)-4 \alpha^{2} c_{s 1} c_{s 2}} \\
y_{s 1}^{D C *}=\frac{2(m-c)(\beta-k) c_{m} c_{s 2}}{4 c_{m} c_{s 1} c_{s 2}-c_{m}(\beta-k)^{2}\left(c_{s 1}+c_{s 2}\right)-4 \alpha^{2} c_{s 1} c_{s 2}}
\end{gathered}
$$




$$
y_{s 2}^{D C *}=\frac{2(m-c)(\beta-k) c_{m} c_{s 1}}{4 c_{m} c_{s 1} c_{s 2}-c_{m}(\beta-k)^{2}\left(c_{s 1}+c_{s 2}\right)-4 \alpha^{2} c_{s 1} c_{s 2}}
$$

Proof. The total profit of the supply chain is:

$$
\pi=(p-c)\left[2 m-2 p+2 \alpha y_{m}+(\beta-k) y_{s 1}+(\beta-k) y_{s 2}\right]-\frac{1}{2} c_{m} y_{m}^{2}-\frac{1}{2} c_{s 1} y_{s 1}^{2}-\frac{1}{2} c_{s 2} y_{s 2}^{2}
$$

Take the derivative of the total supply chain profit with respect to $p, y_{m}, y_{s 1}$ and $y_{s 2}$ by setting $\partial \pi / \partial p=0, \partial \pi / \partial y_{m}=0, \partial \pi / \partial y_{s 1}=0$ and $\partial \pi / \partial y_{s 2}=0$, then we can solve the optimal equilibrium solution.

After substituting the optimal equilibrium solution into Eq. (16), we find that:

$$
\pi^{D C *}=\frac{2(m-c)^{2} c_{m} c_{s 1} c_{s 2}}{4 c_{m} c_{s 1} c_{s 2}-c_{m}(\beta-k)^{2}\left(c_{s 1}+c_{s 2}\right)-4 \alpha^{2} c_{s 1} c_{s 2}}
$$

Proposition 6. Under the situation D, when the sensitivity coefficient of CSR increases, the optimal CSR level of each member and the total profit of the supply chain increase.

Proof. $\frac{\partial \pi^{D C *}}{\partial \alpha}=16 \alpha c_{m} c_{s 1}^{2} c_{s 2}^{2}(m-c)^{2}\left[\frac{1}{4 c_{m} c_{s 1} c_{s 2}-c_{m}(\beta-k)^{2}\left(c_{s 1}+c_{s 2}\right)-4 \alpha^{2} c_{s 1} c_{s 2}}\right]^{2}>0$,

$$
\frac{\partial \pi^{D C *}}{\partial \beta}=4 c_{m}^{2} c_{s 1} c_{s 2}(\beta-k)\left(c_{s 1}+c_{s 2}\right)(m-c)^{2}\left[\frac{1}{4 c_{m} c_{s 1} c_{s 2}-c_{m}(\beta-k)^{2}\left(c_{s 1}+c_{s 2}\right)-4 \alpha^{2} c_{s 1} c_{s 2}}\right]^{2}>0 .
$$

Because $y_{m}^{D C *}>0$, so $4 c_{m} c_{s 1} c_{s 2}-c_{m}(\beta-k)^{2}\left(c_{s 1}+c_{s 2}\right)+4 \alpha^{2} c_{s 1} c_{s 2}>4 c_{m} c_{s 1} c_{s 2}-c_{m}(\beta-k)^{2}\left(c_{s 1}+c_{s 2}\right)-4 \alpha^{2} c_{s 1} c_{s 2}>0$ and $m-c>0$, we can find $\frac{\partial y_{m}^{D C *}}{\partial \alpha}=\frac{4(m-c) c_{s 1} c_{s 2}\left[4 c_{m} c_{s 1} c_{s 2}-c_{m}(\beta-k)^{2}\left(c_{s 1}+c_{s 2}\right)+4 \alpha^{2} c_{s 1} c_{s 2}\right]}{\left[4 c_{m} c_{s 1} c_{s 2}-c_{m}(\beta-k)^{2}\left(c_{s 1}+c_{s 2}\right)-4 \alpha^{2} c_{s 1} c_{s 2}\right]^{2}}>0$. Similarly, we can find $\frac{\partial y_{s 1}^{D C *}}{\partial \beta}>0$ and $\frac{\partial y_{s 2}^{D C *}}{\partial \beta}>0$.

Proposition 7. Under the situation D, with the increase of competition between suppliers, the total profit of supply chain decreases.

Proof. $\frac{\partial \pi^{C *}}{\partial k}=-4 c_{m}^{2} c_{s 1} c_{s 2}(\beta-k)\left(c_{s 1}+c_{s 2}\right)(m-c)^{2}\left[\frac{1}{4 c_{m} c_{s 1} c_{s 2}-c_{m}(\beta-k)^{2}\left(c_{s 1}+c_{s 2}\right)-4 \alpha^{2} c_{s 1} c_{s 2}}\right]^{2}<0$.

\subsection{Decentralized decisions (DD)}


In this case, we also establish a Stackelberg game model dominated by the retailer and followed by suppliers. The decision sequence is as follows: Firstly, the retailer determines $p$ and $y_{m}$; Then, the supplier 1 determines $w_{1}$ and $y_{s 1}$, and the supplier 2 determines $w_{2}$ and $y_{s 2}$ at the same time. For the convenience of calculation, we introduce the retailer's profit margin $x_{i}$ in this section, $x_{i}=p-w_{i}, \quad i=1,2$.

Proposition 8. Under the situation D, the optimal equilibrium solution of the decentralized decision is:

$$
\begin{gathered}
y_{m}^{D D^{*}}=\frac{\alpha(m-c) G^{2}}{H} \\
p^{D D^{*}=} \frac{c_{m}\left[(m+c) \beta^{2} c_{s 2}(k+\beta) \beta\left(k^{2}-\beta^{2}\right)+E \beta^{2}\left(c_{s 1}^{2}+c_{s 2}^{2}\right)(k+\beta)-I \beta c_{s 2} c_{s 1}\left(c_{s 1}+c_{s 2}\right)\right]}{H} \\
+\frac{c_{m}\left[2 c_{s 2}^{2} c_{s 1}^{2}(3 m+c)-2 \beta^{2} c_{s 1} c_{s 2}(\beta+k)(k-2 \beta)(m+c)\right]-c \alpha^{2} G^{2}}{H} \\
w_{1}^{D{ }^{*}}=c+\frac{(m-c) c_{m} c_{s 1}\left[\beta(k+\beta)-c_{s 2}\right] G}{H} \\
w_{2}^{D D *}=c+\frac{(m-c) c_{m} c_{s 2}\left[\beta(k+\beta)-c_{s 1}\right] G}{H} \\
y_{s 1}^{D D *}=\frac{(m-c) c_{m} \beta\left[\beta(k+\beta)-c_{s 2}\right] G}{H} \\
y_{s 2}^{D D *}=\frac{(m-c) c_{m} \beta\left[\beta(k+\beta)-c_{s 1}\right] G}{H}
\end{gathered}
$$

Among them, $\begin{aligned} & H=2 c_{m}\left[\beta^{2} c_{s 2}(k+\beta) \beta\left(k^{2}-\beta^{2}\right)+(k+2 \beta) \beta^{2}\left(c_{s 1}^{2}+c_{s 2}^{2}\right)(k+\beta)-(3 k+5 \beta) \beta c_{s 2} c_{s 1}\left(c_{s 1}+c_{s 2}\right)\right. \\ & \left.+4 c_{s 2}^{2} c_{s 1}^{2}-2 \beta^{2} c_{s 1} c_{s 2}(\beta+k)(k-2 \beta)+\beta^{3} c_{s 1}(\beta-k)(k+\beta)^{2}\right]-\alpha^{2}\left[\beta\left(c_{s 2}+c_{s 1}\right)(k+\beta)-2 c_{s 1} c_{s 2}\right]^{2}\end{aligned}$, $G=\beta\left(c_{s 2}+c_{s 1}\right)(k+\beta)-2 c_{s 1} c_{s 2}, \mathrm{E}=2 k m+3 m \beta+c \beta, \mathrm{I}=5 k m+c k+7 m \beta+3 c \beta$.

Proof. In this section, we also use the inverse induction method to solve the equilibrium solution of the subgame model.

Firstly, the supplier 1 determines $w_{1}$ and $y_{s 1}$, and the supplier 2 determines $w_{2}$ and $y_{s 2}$ at the same time. 
International Journal of Social Science and Economic Research

ISSN: $2455-8834$

Volume: 05, Issue: 07 "July 2020"

Take the first derivative of Eq. (14) with respect to $w_{1}$ and $y_{s 1}$ by setting $\partial \pi_{s 1} / \partial w_{1}=0$ and $\partial \pi_{s 1} / \partial y_{s 1}=0$ , and take the first derivative of Eq. (15) with respect to $w_{2}$ and $y_{s 2}$ by setting $\partial \pi_{s 2} / \partial w_{2}=0$ and $\partial \pi_{s 2} / \partial y_{s 2}=0$. We have:

$$
\begin{gathered}
w_{1}=c+\frac{c_{s 1}\left[(m-p)\left(c_{s 2}-\beta^{2}-\beta k\right)+\alpha c_{s 2} y_{m}-\alpha \beta y_{m}(\beta+k)\right]}{\beta^{2}\left(\beta^{2}-k^{2}-c_{s 2}-c_{s 1}\right)+c_{s 1} c_{s 2}} \\
w_{2}=c+\frac{c_{s 2}\left[(m-p)\left(c_{s 1}-\beta^{2}-\beta k\right)+\alpha c_{s 1} y_{m}-\alpha \beta y_{m}(\beta+k)\right]}{\beta^{2}\left(\beta^{2}-k^{2}-c_{s 2}-c_{s 1}\right)+c_{s 1} c_{s 2}} \\
y_{s 1}=\frac{\beta\left[c_{s 2}-\beta(\beta+k)\right]\left(m-p+\alpha y_{m}\right)}{\beta^{2}\left(\beta^{2}-k^{2}-c_{s 2}-c_{s 1}\right)+c_{s 1} c_{s 2}} \\
y_{s 2}=\frac{\beta\left[c_{s 1}-\beta(\beta+k)\right]\left(m-p+\alpha y_{m}\right)}{\beta^{2}\left(\beta^{2}-k^{2}-c_{s 2}-c_{s 1}\right)+c_{s 1} c_{s 2}}
\end{gathered}
$$

Then, the retailer determines $p$ and $y_{m}$.

Substitute Eqs. (17)-(20) into Eq. (13), and derive the first-order conditions on $p$ and $y_{m}$. We can find the optimal equilibrium solution of $p$ and $y_{m}$ :

$$
\begin{gathered}
y_{m}^{D D *}=\frac{\alpha(m-c) G^{2}}{H} \\
p^{D D *}=\frac{c_{m}\left[(m+c) \beta^{2} c_{s 2}(k+\beta) \beta\left(k^{2}-\beta^{2}\right)+E \beta^{2}\left(c_{s 1}^{2}+c_{s 2}^{2}\right)(k+\beta)-I \beta c_{s 2} c_{s 1}\left(c_{s 1}+c_{s 2}\right)\right]}{H} \\
+\frac{c_{m}\left[2 c_{s 2}^{2} c_{s 1}^{2}(3 m+c)-2 \beta^{2} c_{s 1} c_{s 2}(\beta+k)(k-2 \beta)(m+c)\right]-c \alpha^{2} G^{2}}{H}
\end{gathered}
$$

After substituting Eqs. (21) and (22) into Eqs. (17)-(20), we can obtain the optimal equilibrium solution of the decentralized decision. Then, substitute the optimal equilibrium solution into Eqs. (13)-(15), we can obtain the optimal profit of each member in this case:

$$
\begin{gathered}
\pi_{s 1}^{D D *}=\frac{c_{m}{ }^{2} c_{s 1}(m-c)^{2}\left[\beta(k+\beta)-c_{s 2}\right]^{2}\left(2 c_{s 1}-\beta^{2}\right) G^{2}}{2 H^{2}} \pi_{s 2}^{D D *}=\frac{c_{m}{ }^{2} c_{s 2}(m-c)^{2}\left[\beta(k+\beta)-c_{s 1}\right]^{2}\left(2 c_{s 2}-\beta^{2}\right) G^{2}}{2 H^{2}} \\
\pi_{m}^{D D *}=\frac{(m-c)^{2} c_{m} G^{2}}{2 H}
\end{gathered}
$$




$$
\pi^{D D *}=\pi_{m}^{D D *}+\pi_{s 1}^{D D *}+\pi_{s 2}^{D D *}
$$

\subsection{Two-tariff contract (DF)}

In this case, the retailer provides supplier 1 with the two-tariff contract $\left(x_{1}^{D F}, T_{1}^{D F}\right)$ and supplier 2 with the two-tariff contract $\left(x_{2}^{D F}, T_{2}^{D F}\right)$ respectively.

Proposition 9. Under the situation D, the two-tariff contract also can realize the coordination of the supply chain, so that the optimal decision of supply chain members can reach the level under the centralized decision, and the pareto improvement of profits can be realized.

Proof. The profit functions of retailer, supplier 1 and supplier 2 under contract coordination are:

$$
\begin{gathered}
\pi_{m}=x_{1}^{D F}\left[m-\left(x_{1}^{D F}+w_{1}\right)+\alpha y_{m}+\beta y_{s 1}-k y_{s 2}\right]+x_{2}^{D F}\left[m-\left(x_{2}^{D F}+w_{2}\right)+\alpha y_{m}+\beta y_{s 2}-k y_{s 1}\right]-\frac{1}{2} c_{m} y_{m}^{2}+T_{1}^{D F}+T_{2}^{D F} \\
\pi_{s 1}=\left(w_{1}-c\right)\left[m-\left(x_{1}^{D F}+w_{1}\right)+\alpha y_{m}+\beta y_{s 1}-k y_{s 2}\right]-\frac{1}{2} c_{s 1} y_{s 1}^{2}-T_{1}^{D F} \\
\pi_{s 2}=\left(w_{2}-c\right)\left[m-\left(x_{2}^{D F}+w_{2}\right)+\alpha y_{m}+\beta y_{s 2}-k y_{s 1}\right]-\frac{1}{2} c_{s 2} y_{s 2}^{2}-T_{2}^{D F}
\end{gathered}
$$

Taking the first derivative of Eq. (24) with respect to $y_{s 1}$ by setting $\partial \pi_{s 1} / \partial y_{s 1}=0$ and the first derivative of Eq. (25) with respect to $y_{s 2}$ by setting $\partial \pi_{s 2} / \partial y_{s 2}=0$, we can find $y_{s 1}^{D F *}=\frac{\left(p-x_{1}-c\right) \beta}{c_{s 1}}$ and $y_{s 2}^{D F *}=\frac{\left(p-x_{2}-c\right) \beta}{c_{s 2}}$. Because under contract coordination, the optimal strategy of supply chain members is the same as that under centralized decision, that is, $p^{D F *}=p^{D C *}, y_{m}^{D F *}=y_{m}^{D C *}, y_{s 1}^{D F *}=y_{s 1}^{D C *}, y_{s 2}^{D F *}=y_{s 2}^{D C *}$. Then $\quad$ we can obtain $x_{1}^{D F *}=\frac{2(m-c) k c_{m} c_{s 1} c_{s 2}}{\beta\left[4 c_{m} c_{s 1} c_{s 2}-c_{m}(\beta-k)^{2}\left(c_{s 1}+c_{s 2}\right)-4 \alpha^{2} c_{s 1} c_{s 2}\right]}$ and $x_{2}^{D F *}=\frac{2(m-c) k c_{m} c_{s 1} c_{s 2}}{\beta\left[4 c_{m} c_{s 1} c_{s 2}-c_{m}(\beta-k)^{2}\left(c_{s 1}+c_{s 2}\right)-4 \alpha^{2} c_{s 1} c_{s 2}\right]}$ 。

The optimal profit of each supply chain member under contract coordination can be obtained by substituting the above optimal strategy into Eqs. (23)-(25). Because only when the profit of each member is greater than the profit before the contract coordination, the supply chain member can accept the contract, so we have $\pi_{m}^{D F *} \geq \pi_{m}^{D C *}, \pi_{s 1}^{D F *} \geq \pi_{s 1}^{D C *}, \pi_{s 2}^{D F *} \geq \pi_{s 2}^{D C *}$. Finally, the value range of transfer payment $T_{1}^{D F}$ and $T_{2}^{D F}$ can be obtained from $\pi_{m}^{D F *} \geq \pi_{m}^{D C *}, \pi_{s 1}^{D F *} \geq \pi_{s 1}^{D C *}, \pi_{s 2}^{D F *} \geq \pi_{s 2}^{D C *}$. Due to the complexity of the expression, the specific range will be given in the numerical analysis. 


\section{NUMERICAL ANALYSIS}

In this section, MATLAB is used for numerical analysis to compare and analyze the model equilibrium solutions under different situations, and to study the coordination effect of the twotariff contract and the impact of supplier competition on the optimal strategy. The values of relevant parameters in the model are as follows: $m=100, c=20, c_{s 1}=c_{s 2}=25, c_{m}=30, \alpha=3, \beta=3, k=1$

\section{(1) Comparative analysis of equilibrium solutions in different situations}

From Table 2, we can find that whether one supplier fulfill CSR (situation S) or both suppliers fulfill CSR (situation D), we have $p^{D^{*}}>p^{C^{*}}, y_{m}^{D^{*}}<y_{m}^{C^{*}}, y_{s i}^{D^{*}}<y_{s i}^{C^{*}}, \pi^{D^{*}}<\pi^{C^{*}}$, that is, the retail price under the centralized decision is lower than the retail price under the decentralized decision, and the CSR level of each member and the total profit of the supply chain are higher than the level under the decentralized decision. Under centralized decision, the market demand increases, and consumers can also buy commodities with higher CSR at lower prices, realizing a win-win situation for consumers and all members of the supply chain.

Compared with situation S, we have $p^{D C *}<p^{S C *}, y_{m}^{D C *}<y_{m}^{S C *}, y_{s 1}^{D C *}<y_{s 1}^{S C *}, \pi^{D C *}<\pi^{S C *}$ under situation D, that is, when supplier 2 also fulfills CSR, although the overall CSR level of the supply chain improves, the CSR level of the retailer and supplier 1 as well as the total profit of the supply chain decreases. The positive impact of the decline in retail price on the profit of the supply chain cannot offset the negative impact of the competition between suppliers on the profits of the supply chain. In this case, the CSR behavior of supplier 2 does not fully play a positive role on the whole supply chain, and the CSR undertaking mode that both suppliers fulfill CSR has no obvious advantage.

Table 2: The equilibrium solutions in different situations

\begin{tabular}{ccccc}
\hline & SC & SD & DC & DD \\
\hline$w_{1}^{*}$ & & 51.91 & & 47.40 \\
$w_{2}^{*}$ & & 40.42 & & 47.40 \\
$p^{*}$ & 85.57 & 95.28 & 84.52 & 96.62 \\
$y_{m}^{*}$ & 13.11 & 5.23 & 12.90 & 5.48 \\
$y_{s 1}^{*}$ & 7.87 & 3.83 & 5.16 & 3.29 \\
$y_{s 2}^{*}$ & & & 5.16 & 3.29 \\
$\pi_{m}^{*}$ & & 2093.32 & & 2191.78 \\
$\pi_{s 1}^{*}$ & & 834.98 & & 615.50
\end{tabular}


International Journal of Social Science and Economic Research

ISSN: $2455-8834$

Volume: 05, Issue: 07 "July 2020"

\begin{tabular}{lrrrr}
$\pi_{s 2}^{*}$ & & 417.08 & & 615.50 \\
$\pi^{*}$ & 5245.90 & 3345.38 & 5161.29 & 3422.78 \\
\hline
\end{tabular}

(2) Analysis of contract coordination effect

From Table 3, we can find that under situation $\mathrm{S}$, there are $x_{1}^{S F *}=0, x_{2}^{S F *}=11.80$, and in order to meet individual rational constraints, the transfer payment should satisfy $T_{1}^{S F *} \leq 3464.94, T_{2}^{S F *} \leq 2474.19$ and $T_{1}^{S F *}+T_{2}^{S F *} \geq 4038.60$. Under situation $\mathrm{D}$, there are $x_{1}^{D F *}=x_{2}^{D F *}=21.51$, and also in order to meet individual rational constraints, the transfer payment should satisfy $T_{1}^{D F *} \leq 1826.40, T_{2}^{D F *} \leq 819.08$ and $T_{1}^{D F *}+T_{2}^{D F *} \geq 906.97$.

Table 3: The optimal strategy under contract coordination

\begin{tabular}{ccc}
\hline & $\mathrm{SF}$ & $\mathrm{DF}$ \\
& & \\
\hline$x_{1}^{*}$ & 0 & 21.51 \\
$x_{2}^{*}$ & 11.80 & 21.51 \\
$w_{1}^{*}$ & 85.57 & 63.01 \\
$w_{2}^{*}$ & 73.77 & 63.01 \\
$p^{*}$ & 85.57 & 84.52 \\
$y_{m}^{*}$ & 13.11 & 12.90 \\
$y_{s 1}^{*}$ & 7.87 & 5.16 \\
$y_{s 2}^{*}$ & & 5.16 \\
$\pi_{m}^{*}$ & $-1945.28+T_{1}^{S F *}+T_{2}^{S F *}$ & $1284.81+T_{1}^{D F *}+T_{2}^{D F *}$ \\
$\pi_{s 1}^{*}$ & $4299.92-T_{1}^{S F *}$ & $2441.90-T_{1}^{D F *}$ \\
$\pi_{s 2}^{*}$ & $2891.27-T_{2}^{S F *}$ & $1434.58-T_{2}^{D F *}$ \\
$\pi^{*}$ & 5245.90 & 5161.29 \\
\hline
\end{tabular}

From Table 4 and Table 5, we can find that under the contract coordination, the manufacturer's profit, the supplier's profit and the total profit of the supply chain are all larger than the level under the decentralized decision, realizing the Pareto improvement of the profit. Moreover, as the dominator of the supply chain, the retailer's profit growth is larger than that of the suppliers. The retailer's profits increase with the increase of the transfer payment, while the suppliers' profits decrease with the increase of the transfer payment. 
Table 3, Table 4 and Table 5 show that when the contract parameters meet the above conditions, the two-tariff contract can effectively coordinate the supply chain, so that the optimal price decision, CSR decision and total profit of the supply chain can reach the level under the centralized decision, and the pareto improvement can be realized for each member of the supply chain.

Table 4: Change of profit under different values of transfer payment under situation $S$

\begin{tabular}{llllll}
\hline$T_{1}^{S F}$ & $T_{2}^{S F}$ & $\pi_{C}^{S F}$ & $\pi_{m}^{S F}$ & $\pi_{s 1}^{S F}$ & $\pi_{s 2}^{S F}$ \\
\hline 3464 & 2474 & 5245.90 & 3992.72 & 835.92 & 417.27 \\
3434 & 2444 & 5245.90 & 3932.72 & 865.92 & 447.27 \\
3404 & 2414 & 5245.90 & 3872.72 & 895.92 & 477.27 \\
3374 & 2384 & 5245.90 & 3812.72 & 925.92 & 507.27 \\
3344 & 2354 & 5245.90 & 3752.72 & 955.92 & 537.27 \\
\hline
\end{tabular}

Table 5: Change of profit under different values of transfer payment under situation D

\begin{tabular}{llllll}
\hline$T_{1}^{D F}$ & $T_{2}^{D F}$ & $\pi_{C}^{D F}$ & $\pi_{m}^{D F}$ & $\pi_{s 1}^{D F}$ & $\pi_{s 2}^{D F}$ \\
\hline 1826 & 819 & 5161.29 & 3929.81 & 615.90 & 615.58 \\
1806 & 799 & 5161.29 & 3889.81 & 635.90 & 635.58 \\
1786 & 779 & 5161.29 & 3849.81 & 655.90 & 655.58 \\
1766 & 759 & 5161.29 & 3809.81 & 675.90 & 675.58 \\
1746 & 739 & 5161.29 & 3769.81 & 695.90 & 695.58 \\
\hline
\end{tabular}

(3) The influence of competition degree on optimal strategy and profit under situation D

It can be seen from Figure 1 (where the CSR level curve and contract parameter curve of the two suppliers overlap) that with the intensification of competition between suppliers, retail price, retailer CSR level and supplier CSR level all show a downward trend, and the optimal total profit of the supply chain also declines (as can be seen from proposition 7). Therefore, the positive impact of retail price decline on market demand cannot eliminate the negative impact of CSR level decline. The CSR level of suppliers is greatly affected by the degree of competition, while that of the retailer is less affected. And with the increase of competition, the marginal profit of the retailer also increases, which means that retailers lack the motivation to motivate suppliers, which is not conducive to the cooperation between the retailer and suppliers. As can be seen from Figure 2, the intensified competition among suppliers will reduce the profit of all supply chain members as well as the total profit of the supply chain, which is not beneficial to any supply chain member. 
Therefore, in general, the competition between suppliers is not conducive to the development of the whole supply chain. Suppliers should take measures to reduce the degree of competition to improve the CSR level of the whole supply chain, so as to improve the profit of the whole supply chain and finally achieve a win-win situation.

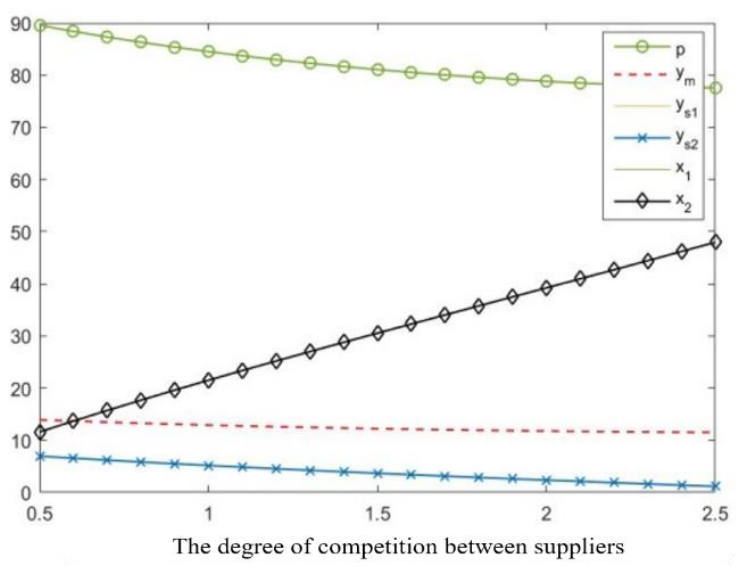

Figure 1. The influence of competition degree on optimal strategy

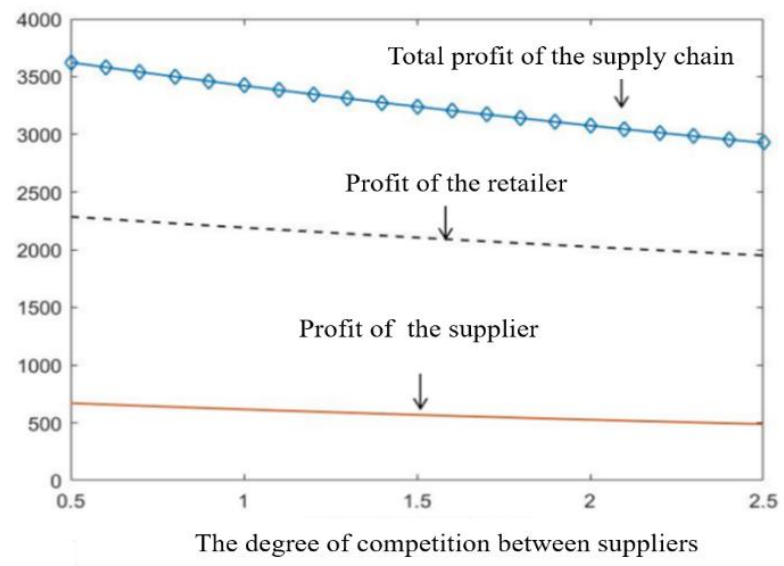

Figure 2. The influence of competition degree on profit

\section{CONCLUSION AND PROSPECT}

A supply chain consisting of two competing suppliers and a single retailer is studied. Under the premise that the retailer fulfills CSR, a game model is established to solve the optimal decision in the case that a single supplier fulfills CSR and both suppliers fulfill CSR, and the two-tariff contract is used to realize the coordination of the supply chain. Finally, we compare the equilibrium solutions in different situations by numerical analysis, and studies the conditions to be satisfied by the parameters of the contract, as well as the influence of competition coefficient on the optimal strategy of supply chain. Based on the above research, we obtain the following conclusions:

(1) Under situation $\mathrm{S}$ and situation $\mathrm{D}$, the two-tariff contract can realize the coordination of the supply chain, making the equilibrium solution reach the optimal level under the centralized decision.

(2) Compared with situation S, under situation D, the retail price decreases and the overall CSR level of the supply chain increases, but the CSR level of the retailer and supplier 1 decreases as well as the total profit. Therefore, the CSR undertaking mode that both suppliers fulfill CSR has no obvious advantages compared with the CSR undertaking mode that single supplier fulfills CSR. 
International Journal of Social Science and Economic Research

ISSN: $2455-8834$

Volume: 05, Issue: 07 "July 2020"

(3) As the degree of competition between suppliers increases, the profit of each member of the supply chain and the optimal CSR level decline. The competition among suppliers is not conducive to the overall development of the supply chain. Therefore, certain incentive mechanisms should be adopted to promote suppliers to reach certain cooperation.

(4) With the improvement of consumers' CSR recognition, the CSR level and total profit of the supply chain will both increase. Therefore, enterprises should cooperate with relevant departments to carry out appropriate publicity on CSR to improve the consumer's CSR recognition.

There are still many deficiencies in our research. For example, we assume information symmetry among supply chain members, but in reality, information asymmetry among supply chain members is more common. In addition, we assume that the manufacturer is dominant in the supply chain system and does not consider different channel power structures. In the future, we will start from these deficiencies to carry out a further study.

\section{REFERENCES}

[1] Xie C, Bagozzi R P, Grønhaug K. The impact of corporate social responsibility on consumer brand advocacy: The role of moral emotions, attitudes, and individual differences [J]. Journal of Business Research, 2019, 95: 514-530.

[2] Mishra D R. Post-innovation CSR performance and firm value [J]. Journal of Business Ethics, 2017, 140(2): 285-306.

[3] Huang S P. Empirical Research on the Influence of Corporate social responsibility on corporate image -- Empirical Evidence from China's banking industry [J]. Research on Economics and Management, 2012, (7): 121-128.

[4] Deng X M, Zhang T, Xu Y, et al. Research on the Influence of Corporate Social Responsibility on Consumers' Purchase Intention [J]. Chinese Journal of Management, 2016, 13(7): 1019-1027.

[5] Ma P, Shang J, Wang H. Enhancing corporate social responsibility: Contract design under information asymmetry [J]. Omega, 2017, 67: 19-30.

[6] Goering G E. Corporate social responsibility and marketing channel coordination [J]. Research in Economics, 2012, 66(2): 142-148. 
International Journal of Social Science and Economic Research

ISSN: $2455-8834$

Volume: 05, Issue: 07 "July 2020"

[7] Liu Y, Quan B, Xu Q, et al. Corporate social responsibility and Decision Analysis in a Supply Chain through government subsidy [J]. Journal of Cleaner Production, 2019, 208: 436-447.

[8] Bian J, Li K W, Guo X, et al. A strategic analysis of incorporating CSR into managerial incentive design [J]. Transportation Research Part E-logistics and Transportation Review, 2016, 86(86): 83-93.

[9] Hsueh C. Improving corporate social responsibility in a supply chain through a new revenue sharing contract [J]. International Journal of Production Economics, 2014, 151(151): 214-222.

[10] Fan J C, Ni D B, Tang X W. Research on Corporate Social Responsibility and Supply Chain Product Quality Selection and Coordination Contract. Chinese Journal of Management, 2017, 14(09): 1374-1383.

[11] Xing P, Zhang C H, Li C Y. An optimal strategy for Service Supply Chain considering Social Responsibility and Quality Effort [J]. Journal of Northeastern University (Natural Science), 2017, 38(06): 898-902.

[12] Duan H W, Yan Y S, Zhang Y D. Research on Pricing and Coordination of Logistics Service Supply Chain considering CSR [J].Control and Decision, 2016, 31(12): 22872292.

[13] Li X R, Li G. Research on coordination mechanism of a two-stage closed-loop supply chain considering CSR. Chinese Journal of Management Science. https://doi.org/10.16381/j.cnki.issn1003-207x.2019.1235

[14] Huang Y. A Closed-Loop Supply Chain with Trade-In Strategy under Retail Competition [J]. Mathematical Problems in Engineering, 2018: 1-16.

[15] Zhou Y, Hu F, Zhou Z, et al. Pricing decisions and social welfare in a supply chain with multiple competing retailers and carbon tax policy [J]. Journal of Cleaner Production, 2018: 752-777.

[16] Wang W D, Li X Y. Study on the Coordination of Low-carbon Supply Chain Considering the Competition and Information Asymmetry [J]. Industrial Engineering and Management, 2020, 25(03): 27-33. 
[17] Sun Y C, Yang Z L, Wang J P.Two-manufacturer one-retailer supply chain coordination model with demand depending on effort level [J]. Journal of Hefei University of Technology (Natural Science), 2014, 37(07): 871-876.

[18] Qin X H.The coordination mechanism of online shopping service supply chain considering fairness under multi-source procurement mode [J]. Journal of Chongqing Technology and Business University (Natural Science), 2018, 35(4): 82-87.

[19] Wang Q W, Gao Y. Study on strategy for enterprise alliance among 2 manufacturers and 1 retailer in closed-loop supply chain [J]. Application Research of Computers, 2016, 33(11): 3289-3292+3319.

[20] Wang Y L, Jian M, Fang X, Wang N N. Coordination of supply chain considering bilateral effort levels affect demand and return [J]. Computer Integrated Manufacturing Systems, 2018, 24(10): 2622-2630. 